\title{
Effect of calcination temperature and reaction conditions on methane partial oxidation using lanthanum-based perovskite as oxygen donor
}

\author{
DAI Xiaoping (代小平) $)^{1,2}$, YU Changchun (余长春) $)^{1}$, LI Ranjia (李然家) ${ }^{1}$, WU Qiong (吴 琼) ${ }^{1}$, SHI Kaijiao (史凯娇) ${ }^{1}$, \\ HAO Zhengping (郝郑平) ${ }^{2}$ \\ (1. The Key Laboratory of Catalysis CNPC, University of Petroleum, Beijing 102249, China; 2. Research Center for Eco-Environmental Science, Chinese Academy of \\ Sciences, Beijing 100085, China)
}

Received 10 June 2007; revised 22 July 2007

\begin{abstract}
We investigated the effect of calcination temperature, reaction temperature, and different amounts of replenished lattice oxygen on the partial oxidation of methane (POM) to synthesis gas using perovskite-type $\mathrm{LaFeO}_{3}$ oxide as oxygen donor instead of gaseous oxygen, which was prepared by the sol-gel method, and the oxides were characterized by XRD, TG/DTA, and BET. The results indicated that the particle size increased with the calcination temperature increasing, while $\mathrm{BET}$ and $\mathrm{CH}_{4}$ conversion declined with the calcination temperature increasing using $\mathrm{LaFeO}_{3}$ oxide as oxygen donor in the absence of gaseous oxygen. $\mathrm{CO}$ selectivity remained at a high level such as above $92 \%$, and increased slightly as the calcination temperature increased. Exposure of $\mathrm{LaFeO}_{3}$ oxides to methane atmosphere enhanced the oxygen migration of in the bulk with time online owing to the loss of lattice oxygen and reduction of the oxidative stated Fe ion simultaneously. The high reaction temperature was favorable to the migration of oxygen species from the bulk toward the surface for the synthesis gas production with high CO selectivity. The product distribution and evolution for POM by sequential redox reaction was determined by amounts of replenished lattice oxygen with gaseous oxygen. The optimal process should decline the total oxidation of methane, and increase the selectivity of partial oxidation of methane.
\end{abstract}

Keywords: perovskite $\mathrm{LaFeO}_{3}$; lattice oxygen; synthesis gas; redox reaction; rare earths

Renewed interest in methane conversion to synthesis gas, which can be used to produce a variety of chemicals by the Fischer-Tropsch and methanol synthesis, has arisen. Currently, large-scale industrial route for synthesis gas production was based on steam reforming of methane, which was a capital- and energy-intensive process owing to the highly endothermic nature of the reaction and also a large $\mathrm{H}_{2} / \mathrm{CO}$ ratio. The catalytic partial oxidation (CPO) offered the greatest potential for an efficient and economical conversion of methane to synthesis gas, owing to the high selectivity and suitable $\mathrm{H}_{2} / \mathrm{CO}$ ratio, but the Ni-based catalyst exhibited a rapid deactivation because of carbon deposition that has been reported ${ }^{[1]}$. Recently, a novel method for synthesis gas production by the direct use of lattice oxygen of perovskite has been proposed by our group ${ }^{[2-4]}$. This new route was superior to general partial oxidation of methane (POM) in stability (resistance to carbonaceous deposition), safety (avoiding effectively the accidental explosion), easy operation and optimization, and low cost (making use of air not oxygen) ${ }^{[4]}$. The present study aimed to explore the effect of calcination temperature and reaction temperature on cata- lytic activity for POM over perovskite-type $\mathrm{LaFeO}_{3}$ oxide using lattice oxygen, and the product distribution was investigated by controlling the amount of replenished lattice oxygen with gaseous oxygen.

\section{Experimental}

\subsection{Catalyst preparation}

A sol-gel method was employed to prepare the samples. Powders of $\mathrm{La}\left(\mathrm{NO}_{3}\right)_{3} \cdot 6 \mathrm{H}_{2} \mathrm{O}(>99 \%$, Beijing Chemical Company), $\mathrm{Fe}\left(\mathrm{NO}_{3}\right)_{3} \cdot 9 \mathrm{H}_{2} \mathrm{O}$ (>99\%, Beijing Chemical Company) were weighed to achieve equimolar amounts and dissolved in a small amount of distilled water. Glycine (>99\%, Beijing Chemical Company) was kept at a ratio of $\mathrm{NH}_{2} / \mathrm{NO}_{3}^{-}=1.05$ to prepare the gel, where $\mathrm{NH}_{2}$ originated from glycine, and $\mathrm{NO}_{3}^{-}$originated from $\mathrm{La}\left(\mathrm{NO}_{3}\right)_{3} \cdot 6 \mathrm{H}_{2} \mathrm{O}$ and $\mathrm{Fe}\left(\mathrm{NO}_{3}\right)_{3} \cdot 9 \mathrm{H}_{2} \mathrm{O}$. Gelation was induced by heating the solution at $80-90{ }^{\circ} \mathrm{C}$; this temperature was maintained for $10 \mathrm{~h}$, then heated to $250{ }^{\circ} \mathrm{C}$ and kept for 30 min with a fast decomposition reaction, upon which a dried powder precursor

Foundation item: Project supported by the National Natural Science Foundation of China $(20306016,20322201)$

Corresponding author: YU Changchun, HAO Zhengping (E-mail: ingcc@ @ cup.edu.cn: zpinghao@ rcees.ac.cn: Tel.: +86-10-89707447; +86-10-62923564) 
was obtained. Thus, obtained portions of such precursor were then fired in a muffle oven at different temperatures (namely, 800, 900, 1000 , and $1100{ }^{\circ} \mathrm{C}$ for $6 \mathrm{~h}$ ) at a heating rate of $10^{\circ} \mathrm{C} / \mathrm{min}$.

\subsection{Catalyst characterization}

Thermal decomposition of $\mathrm{LaFeO}_{3}$ precursor was investigated by thermogravimetry (TG, Seteram, Labsys). In a typical measurement, $30 \mathrm{mg}$ of sample was heated in an $\mathrm{Al}_{2} \mathrm{O}_{3}$ crucible at a constant heating rate of $10{ }^{\circ} \mathrm{C} / \mathrm{min}$ from $60{ }^{\circ} \mathrm{C}$ to $1200{ }^{\circ} \mathrm{C}$, with air purging at a flow rate of 30 $\mathrm{ml} / \mathrm{min}$. Powder X-ray diffraction (XRD) patterns were recorded from $2 \theta=20^{\circ}$ to $80^{\circ}$ at a speed of $4\left(^{\circ}\right) / \mathrm{min}$ and $0.02^{\circ}$ step size using a ShiDU XRD-6000 powder diffractometer employing Ni-filtered $\mathrm{Cu} \mathrm{K} \alpha$ radiation. The crystallite size of the samples was calculated from the full width at half maximum of the most intense diffraction peak using Scherrer's equation.

The specific surface area of the samples was determined by applying the BET method to nitrogen adsorption isotherms recorded at $-196{ }^{\circ} \mathrm{C}$, using a Quantachrome NOVA1200 gas absorption analyzer.

\subsection{Catalytic performance by continuous flow reaction}

Catalytic performance was investigated in $\mathrm{CH}_{4} / \mathrm{Ar}$ over $0.25 \mathrm{~g} \mathrm{LaFeO}_{3}$ oxides at $900{ }^{\circ} \mathrm{C}$ by continuous flow reaction. The samples were pretreated in an $\mathrm{O}_{2}$ flow $\left(\mathrm{O}_{2} / \mathrm{Ar}=11 \%\right.$, total flow rate $=23 \mathrm{ml} / \mathrm{min}$ ) at reaction temperature for $30 \mathrm{~min}$. Then the gas was switched to pure $\mathrm{Ar}$ (total flow rate $=23$ $\mathrm{ml} / \mathrm{min}$ ) for about $30 \mathrm{~min}$ for removing gas phase oxygen. Finally, the gas was switched to $11 \% \mathrm{CH}_{4} / \mathrm{He}$ (mol, total flow rate $=23 \mathrm{ml} / \mathrm{min}$ ) for the reaction to occur.

\subsection{Sequential redox reaction for replenished lattice oxygen}

The amount of replenished lattice oxygen with gaseous oxygen, which was determined by preliminary experiments, was controlled by sequential redox reaction between reductive $\left(\mathrm{CH}_{4} / \mathrm{He}\right)$ and oxidative atmospheres $\left(\mathrm{O}_{2} / \mathrm{Ar}\right)$ in a fixed-bed reactor. The $0.25 \mathrm{~g}$ samples reacted with methane first, then switched to $\mathrm{O}_{2} / \mathrm{He}$ for replenishing the consumed oxygen species, and then switched to $\mathrm{CH}_{4} / \mathrm{Ar}$ at $900{ }^{\circ} \mathrm{C}$. The total gas flow rate was $25 \mathrm{ml} / \mathrm{min}$. Ar/He was used as dilution gas and tracer gas. The ratios of the amount of replenished lattice oxygen and that of the full oxidation were $20 \%$, $40 \%, 60 \%, 80 \%$, and $100 \%$, respectively.

The reactant and products were detected using the mass spectrometer at $\mathrm{m} / \mathrm{e}=2\left(\mathrm{H}_{2}\right), \mathrm{m} / \mathrm{e}=15\left(\mathrm{CH}_{4}\right), \mathrm{m} / \mathrm{e}=18\left(\mathrm{H}_{2} \mathrm{O}\right)$, $\mathrm{m} / \mathrm{e}=28(\mathrm{CO}), \mathrm{m} / \mathrm{e}=32\left(\mathrm{O}_{2}\right)$, and $\mathrm{m} / \mathrm{e}=44\left(\mathrm{CO}_{2}\right)$, where, $\mathrm{m} / \mathrm{e}$ indicates the mass to charge ratio. The pure $\mathrm{CH}_{4}, \mathrm{CO}, \mathrm{H}_{2}$, and $\mathrm{CO}_{2}$ pulses were injected to calculate the amount of $\mathrm{CH}_{4}$,
$\mathrm{CO}$, and $\mathrm{CO}_{2}$ on the oxides taking into account a previous calibration of the mass spectrometer. The calibration of the mass spectrometer was carried out with standard gas mixtures (known composition). The cracking coefficients of methane, $\mathrm{CO}$, and $\mathrm{CO}_{2}$ were determined and used to calculate their concentrations. The $\mathrm{CO}$ selectivity was defined as $\mathrm{CO} /\left(\mathrm{CO}+\mathrm{CO}_{2}\right) \times 100 \%$.

\section{Results and discussion}

\subsection{Influence of calcination temperature on crystalliza- tion and catalytic performance}

Fig.1 displays the TG/DTA curves for the powder precursor obtained after a fast decomposition reaction at $250^{\circ} \mathrm{C}$ for $30 \mathrm{~min}$ (see Experimental). A relatively small weight loss (of ca. 5.2\%) is observed between 60 and ca. $555^{\circ} \mathrm{C}$, in correlation with a broad exothermic peak. After the decomposition reaction at $250^{\circ} \mathrm{C}$ for $30 \mathrm{~min}$, water and most of the Glycine is removed, but a substantial amount of glycine can remain adsorbed on the gel, which is ascribed to the burning of the residual organic components ${ }^{[5]}$. An apparent weight loss (ca. 4.8\%) is produced between ca. 582 and $900{ }^{\circ} \mathrm{C}$ in coincidence with the observation of a relatively large exothermic peak, which shows the formation of a crystalline phase oxide. This process most likely corresponds mainly to an oxygen loss resulting in the final generation of the perovskite phase $\mathrm{e}^{[6-8]}$.

The crystal structure of the samples calcined at different temperatures was analyzed by XRD (Fig.2). The results show that $\mathrm{LaFeO}_{3}$ samples are single-phase perovskites (orthorhombic; Pnma space group), compared with the XRD data of the perovskite structure oxide (JCPDS card No. 37-1493: $2 \theta=32.190$ (100\%), 57.399 (39\%), 46.144 (30\%), 39.674 (18\%), 22.606 (17\%), 67.349 (15\%), $78.641(11 \%)$ ). The crystalline size and intensity are, as expected, observed to increase with the calcination temperature increasing, and appear relatively small for the sample calcined at lower

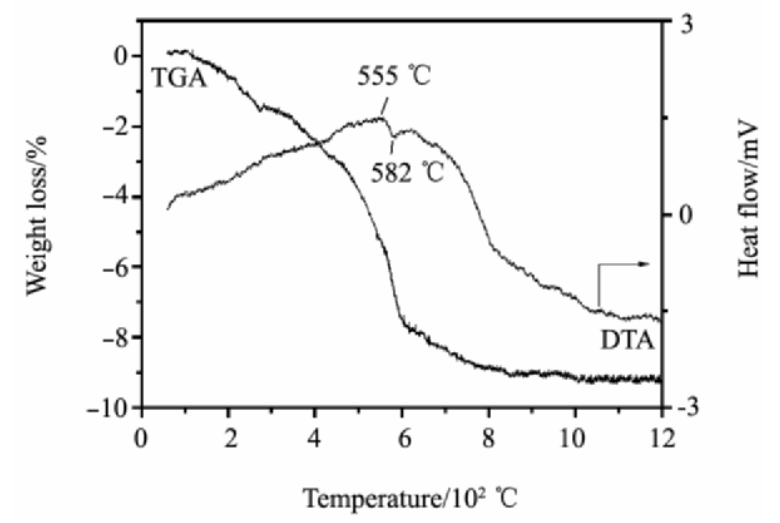

Fig.1 TGA/DTA curves for $\mathrm{LaFeO}_{3}$ powder precursor 


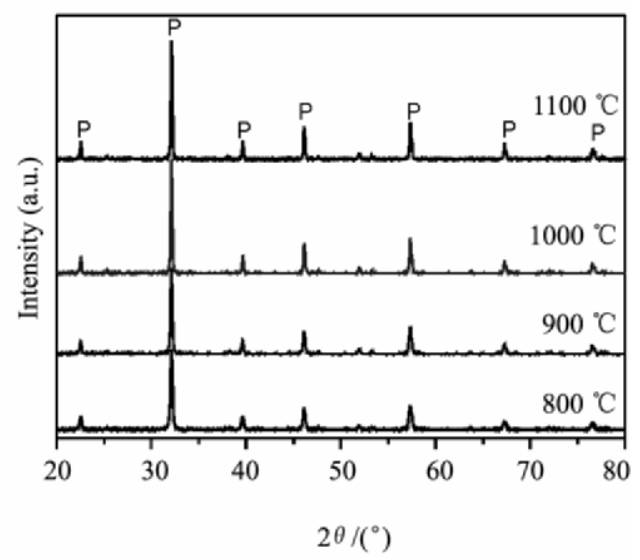

Fig. 2 X-ray diffraction patterns obtained for the $\mathrm{LaFeO}_{3}$ samples at different calcination temperatures for $6 \mathrm{~h}$, where, $\mathrm{P}$ indicates the perovskite phase

temperature. Further data for the crystalline $\mathrm{LaFeO}_{3}$ phase extracted from these diffraction results are collected in Table 1. Practically, no obvious volume change is detected for this phase upon changing the calcination temperature while the primary particle size increases with increasing the calcination temperature, in qualitative agreement with the decrease in specific surface area.

Fig. 3 presents the results of the methane partial oxidation experiments performed by continuous flow reaction over $\mathrm{LaFeO}_{3}$ oxide calcined at different temperatures for $6 \mathrm{~h}$. It is observed that the lower the calcination temperature, the higher is the methane conversion that can be obtained. Especially, the higher the calcination temperature, the methane conversion declines more obviously, while $\mathrm{CO}$ selectivity remains at a high level above $92 \%$, and increases slightly as the calcination temperature increases. The effects of calcination temperature for partial oxidation of methane are as follows: On one hand, it is favorable to produce more oxygen vacancies in which active oxygen are formed. On the other hand, the methane conversion drops because of the decrease

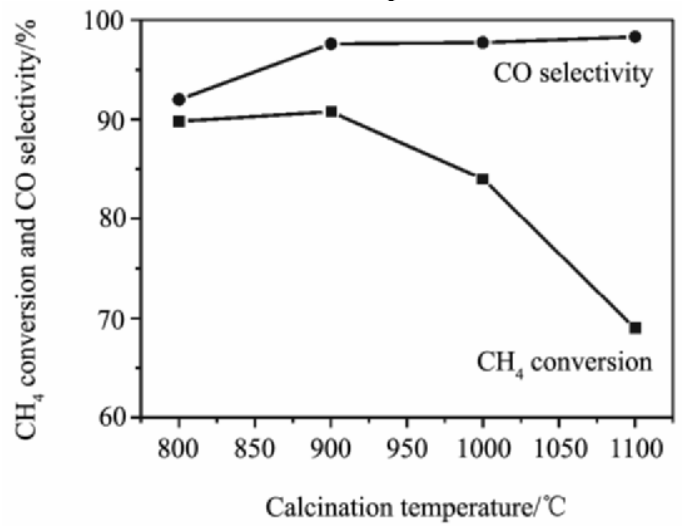

Fig. $3 \mathrm{CH}_{4}$ conversion, $\mathrm{CO}$ selectivity vs. calcination temperature over $\mathrm{LaFeO}_{3}$ oxides for 5 min by continuous flow reaction of surface area as the calcination temperature increases, as shown in Table 1. The catalytic performance of the $\mathrm{LaFeO}_{3}$ sample is relevant with the crystalline size and the rate of oxygen migration from bulk toward surface. Another side is that oxygen vacancy order to disorder transition occurs when temperature increases, which can decrease the mobility of oxygen species in the bulk ${ }^{[9,10]}$, and result in the decreasing methane conversion.

From Fig.4, the oxygen amount of every $50 \mathrm{~s}$ cumulative data for $\mathrm{CO}$ formation at different calcination temperatures is the highest at lower calcination temperature. As the contact time with methane increases, the total oxygen amount for $\mathrm{CO}$ formation increases. The amount of oxygen of every $50 \mathrm{~s}$ cumulative data for $\mathrm{CO}$ formation increases with time on line, especially for the $\mathrm{LaFeO}_{3}$ oxide of high calcination temperature (Table 2), which indicates that the effects of cal-

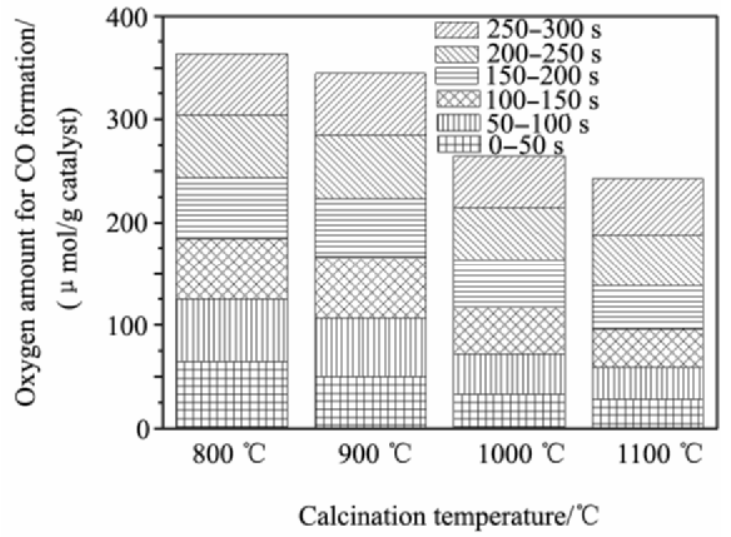

Fig.4 Oxygen amount of every $50 \mathrm{~s}$ cumulative data for $\mathrm{CO}$ formation at different calcination temperatures

Table 1 Crystalline size and BET area for $\mathrm{LaFeO}_{3}$ samples calcined at different temperatures

\begin{tabular}{llll}
\hline $\begin{array}{l}\text { Calcination } \\
\text { conditions }\end{array}$ & $\begin{array}{l}\text { crystalline } \\
\text { size/nm }\end{array}$ & $\begin{array}{l}\text { Unit cell volume } \\
/ \mathrm{nm}^{3}\end{array}$ & $\begin{array}{c}\text { BET area/ } \\
\left(\mathrm{m}^{2} / \mathrm{g}\right)\end{array}$ \\
\hline $800{ }^{\circ} \mathrm{C}, 6 \mathrm{~h}$ & 31.7 & 0.24468 & 12.56 \\
$900{ }^{\circ} \mathrm{C}, 6 \mathrm{~h}$ & 40.0 & 0.24474 & 8.56 \\
$1000{ }^{\circ} \mathrm{C}, 6 \mathrm{~h}$ & 50.7 & 0.24438 & 4.14 \\
$1100{ }^{\circ} \mathrm{C}, 6 \mathrm{~h}$ & 53.5 & 0.24431 & 2.36 \\
\hline
\end{tabular}

Table 2 Oxygen amount of every 50 s cumulative data for $\mathrm{CO}$ formation at different calcination temperatures ( $\mu \mathrm{mol} / \mathrm{g}$ catalyst)

\begin{tabular}{lllllll}
\hline \multirow{2}{*}{$\begin{array}{c}\text { Temper- } \\
\text { ature } /{ }^{\circ} \mathrm{C}\end{array}$} & $0-50$ & $50-100$ & $100-150$ & $150-200$ & $200-250$ & $250-300$ \\
\cline { 2 - 7 } & $010 \mathrm{n} / \mathrm{s}$ & & & & & \\
\hline 800 & 64.65 & 61.18 & 58.02 & 59.28 & 60.86 & 59.67 \\
900 & 50.18 & 56.98 & 57.68 & 58.75 & 60.67 & 60.02 \\
1000 & 33.00 & 39.34 & 44.64 & 46.67 & 50.15 & 50.69 \\
1100 & 28.45 & 30.69 & 36.84 & 42.72 & 48.64 & 54.93 \\
\hline
\end{tabular}


cination temperature occur on the surface layer lattice oxygen. Exposure of $\mathrm{LaFeO}_{3}$ oxides to a reduced atmosphere can generate oxygen vacancies owing to the loss of lattice oxygen and reduction of the oxidative stated Fe ion simultaneously, providing pathways of oxygen transport through the lattice ${ }^{[10]}$, which decrease the resistance of oxygen migration and lead to enhancement of oxygen migration.

\subsection{Effects of reaction temperature over $\mathrm{LaFeO}_{3}$ oxide by continuous flow reaction}

The typical product distribution over $\mathrm{LaFeO}_{3}$ Perovskite in Fig.5 indicates that the reactions are initially very fast and produce significant quantities of carbon dioxide and water, originating from the total oxidation of methane at the preliminary stage. When oxygen species in the surface is consumed, carbon dioxide formation declines rapidly to a very low level, while methane intensity quickly declines, which indicates that methane conversion is sharply enhanced. $\mathrm{CO}$ and $\mathrm{H}_{2}$ intensities increase steadily with time, while the $\mathrm{CH}_{4}$ intensity decreases gradually, and the synthesis gas is the

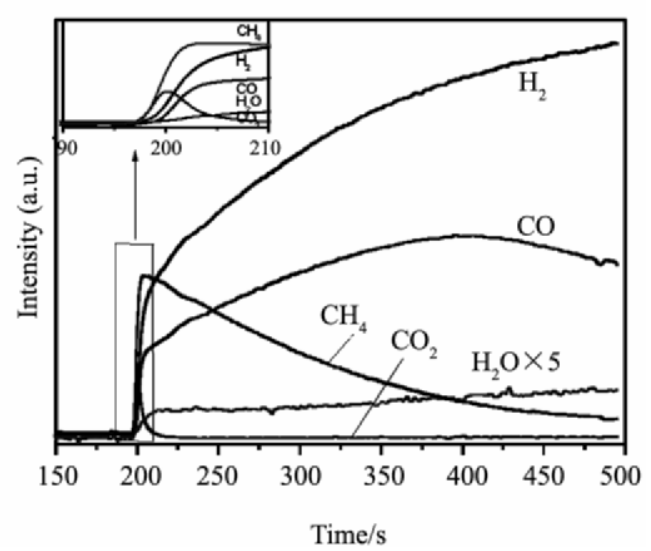

Fig.5 Typical curves of product formation and reagent consumption during continuous flow reaction over fresh $\mathrm{LaFeO}_{3}$ Perovskite at reaction temperature $900{ }^{\circ} \mathrm{C}$

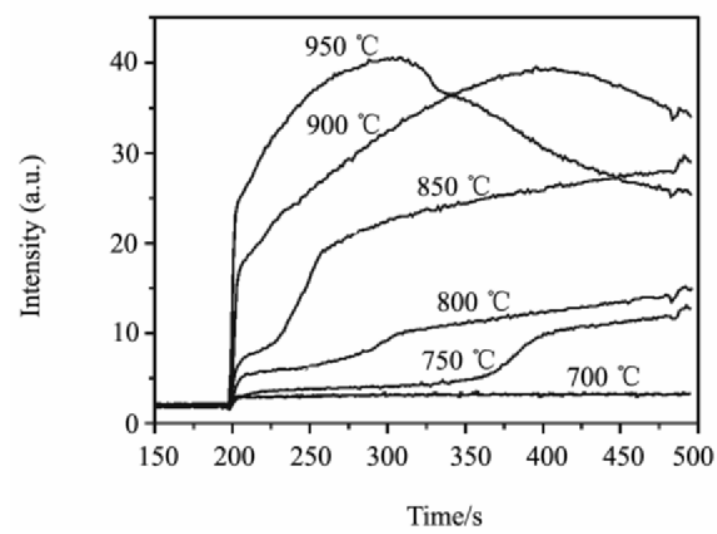

Fig.6 $\mathrm{CO}$ responses switch from $\mathrm{He}$ to $\mathrm{CH}_{4} / \mathrm{Ar}$ at different reaction temperatures over $\mathrm{LaFeO}_{3}$ oxide dominant product. It is noted that the consumption of lattice oxygen on the surface enhances the oxygen mobility from the bulk toward the surface according to the change of the CO slope, which is relevant to the loss of lattice oxygen and reduction of the oxidation state of the $\mathrm{Fe}$ ion simultaneously $^{[11,12]}$. To facilitate the qualitative comparison of the migration rate of lattice oxygen at different temperatures, the CO response is presented in Fig.6, respectively. From Fig.6, it can be seen that the amount of $\mathrm{CO}$ increases sharply when the reaction temperature increases from 700 to $950{ }^{\circ} \mathrm{C}$, owing to the higher migration rate of lattice oxygen at high temperature, but the intensity of $\mathrm{CO}$ decreases first at high reaction temperature $\left(950{ }^{\circ} \mathrm{C}\right)$. The overall oxygen migration in $\mathrm{LaFeO}_{3}$ oxide will be controlled by the interaction between processes: oxygen diffusion in bulk phase and reaction with the methane at the surface. Hence, the mobility of lattice oxygen plays an important role in the partial oxidation of methane without gaseous oxygen. The migration rate of oxygen during the $\mathrm{CH}_{4}$ reaction with $\mathrm{LaFeO}_{3}$ oxide is strongly affected by the reaction temperature. The intensity of $\mathrm{CO}$ increases with reaction temperature, and considerably more $\mathrm{CH}_{4}$ is selectively oxidized to $\mathrm{CO}$ and $\mathrm{H}_{2}$ at high temperatures. The rate of oxygen migration from bulk to surface increases with rising temperature, and more amounts of $\mathrm{CO}$ and $\mathrm{H}_{2}$ are formed.

\subsection{Effect of different amounts of replenished lattice oxygen over $\mathrm{LaFeO}_{3}$ oxide by sequential redox reaction}

The oxidation of hydrocarbons was supposed to occur on the perovskite surface by both suprafacial and intrafacial reaction $^{[13]}$, which involved lattice oxygen in the bulk without gaseous oxygen, and the migration rate of oxygen in the bulk became more and more important for catalytic performance over $\mathrm{LaFeO}_{3}$ perovskite as oxygen donor. The results over $\mathrm{LaFeO}_{3}$ oxide of different amounts of replenished lattice oxygen are shown in Fig.7.

The product profiles in the switch reaction from $\mathrm{O}_{2} / \mathrm{Ar}$ to $\mathrm{CH}_{4} / \mathrm{He}$ on $\mathrm{LaFeO}_{3}$ oxide are shown in Fig.7. There is delay between $\mathrm{H}_{2}, \mathrm{CO}$ and $\mathrm{H}_{2} \mathrm{O}, \mathrm{CO}_{2}$ over $\mathrm{LaFeO}_{3}$ oxide of fully replenished lattice oxygen. With the concentration of surface oxygen declining, $\mathrm{H}_{2}$ and $\mathrm{CO}$ appear over $\mathrm{LaFeO}_{3}$ oxide in the absence of gaseous oxygen. The $\mathrm{CO}_{2}$ and $\mathrm{H}_{2} \mathrm{O}$ are formed first, then $\mathrm{CO}$ and $\mathrm{H}_{2}$ are detected for the switch reaction over $\mathrm{LaFeO}_{3}$ oxide of fully replenished lattice oxygen; however, the intensity of $\mathrm{CO}_{2}$ does not decline immediately when the $\mathrm{CO}$ begins to be detected. There is an initial induction period over $\mathrm{LaFeO}_{3}$ oxide of fully replenished lattice oxygen. However, the $\mathrm{CO}$ and $\mathrm{H}_{2}$ form immediately, and the delay is hardly observed between $\mathrm{H}_{2}, \mathrm{CO}$ and $\mathrm{CO}_{2}, \mathrm{H}_{2} \mathrm{O}$ over $\mathrm{LaFeO}_{3}$ oxide of low amount of replenished lattice oxygen. It is noted that the slope of the $\mathrm{CO}$ curve decreases 

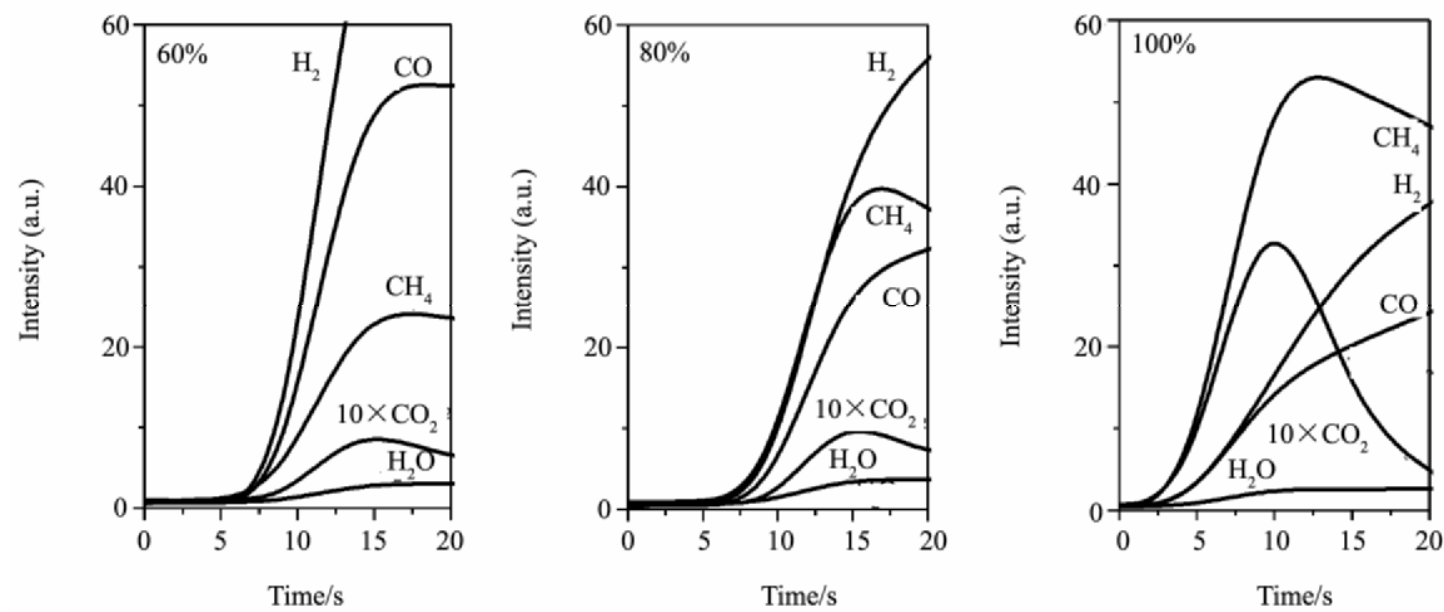

Fig.7 Transient responses of reactant and products switched from $\mathrm{Ar}$ to $\mathrm{CH}_{4}$ over $\mathrm{LaFeO}_{3}$ oxide of different amounts of replenished lattice oxygen at reaction temperature $900^{\circ} \mathrm{C}$

slightly as the amounts of replenished lattice oxygen increase. The oxygen species is believed to be transported by both the surface reaction and the bulk ion conduction mechanism ${ }^{[14]}$. Generally, the synthesis gas formation was favored by the rapid dissociation of methane, which proceeds apparently easier on the reduced surface containing metal/carbide clusters or nuclei ${ }^{[15]}$, but the migration of oxygen species from the bulk toward the surface probably prevents the formation of nuclei of the reduced phases at the surface, and the migration rate of oxygen species in the bulk of oxide depends on the crystalline defect of the bulk of oxide ${ }^{[16]}$. The oxygen species for the $\mathrm{CO}_{2}$ formation can be described as surface anionic vacancies after the reaction of lattice oxygen from the surface. Thereafter, the synthesis gas formation proceeds via the migration of lattice oxygen from the bulk to the surface, which is confirmed by the previous $\operatorname{article}^{[3]}$. The product distribution and evolution for POM by sequential redox reaction is determined by the amounts of replenished lattice oxygen with gaseous oxygen.

\section{Conclusion}

The effects of calcination temperature, reaction temperature, and different amounts of replenished lattice oxygen on methane partial oxidation (POM) over perovskite-type La$\mathrm{FeO}_{3}$ oxide prepared by the sol-gel method were investigated by the continuous flow reaction and the sequential redox reaction. The particle size and BET surface area were affected significantly by the calcination temperature. The $\mathrm{CH}_{4}$ conversion declined with calcination temperature increase, while the $\mathrm{CO}$ selectivity remained at a high level of $92 \%$, and increased slightly as the calcination temperature increased. The higher reaction temperature was favorable to the conversion of $\mathrm{CH}_{4}$ to synthesis gas with high selectivity, and enhanced the migration rate of oxygen species from the bulk toward the surface. The product distribution for POM by sequential redox reaction was determined by the amounts of replenished lattice oxygen with gaseous oxygen. Therefore, the process for synthesis gas production by sequential redox reaction using oxygen donor in the absence of gaseous oxygen could be optimized by controlling appropriate amounts of replenished lattice oxygen with gaseous oxygen.

\section{References:}

[1] Mei D J, Chen Y Q, Zhong J B, Wei Z L, Ma D, Gong M C. Catalytic Partial Oxidation of Methane over $\mathrm{Ni} / \mathrm{CeO}_{2}-\mathrm{ZrO}_{2}$ $\mathrm{Al}_{2} \mathrm{O}_{3}$. J. Rare Earths, 2007, 25(3): 311.

[2] Li R J, Yu C C, Dai X P, Shen S K. Selective Oxidation of Methane to Synthesis Gas Using Lattice Oxygen from Perovskite $\mathrm{La}_{0.8} \mathrm{Sr}_{0.2} \mathrm{FeO}_{3}$ Catalyst. Chin. J. Catal., 2002, 23 (6): 549.

[3] Dai X P, Li R J, Yu C C, Hao Z P. Unsteady-state direct partial oxidation of methane to synthesis gas in a fixed-bed reactor using $\mathrm{AFeO}_{3}(\mathrm{~A}=\mathrm{La}, \mathrm{Nd}, \mathrm{Eu})$ perovskite-type oxides as oxygen storage. J. Phys. Chem. B., 2006, 110(45): 22525.

[4] Dai X P, Wu Q, Li R J, Yu C C, Hao Z P. Hydrogen production from a combination of the water-gas shift and redox cycle process of methane partial oxidation via lattice oxygen over $\mathrm{LaFeO}_{3}$ perovskite catalyst. J. Phys. Chem. B., 2006, 110(51): 25856.

[5] Qi X W, Zhou J, Yue Zh X, Li L T. A simple way to prepare nanosized $\mathrm{LaFeO}_{3}$ powders at room temperature. Ceram. Int., 2003, 29(3): 347.

[6] Duran P, Tartaj J, Capel F, Moure C. Formation, sintering and thermal expansion behaviour of $\mathrm{Sr}$ - and $\mathrm{Mg}$-doped $\mathrm{LaCrO}_{3}$ as SOFC interconnector prepared by the ethylene glycol polymerized complex solution synthesis method. J. Eur. Ceram. Soc., 2004, 24(9): 2619.

[7] Bilger S, Blaß G, Förthman R. Sol-gel synthesis of lanthanum 
chromite powder. J. Eur. Ceram. Soc., 1997, 17(8): 1027.

[8] Carter J D, Anderson H U, Shumsky M G. Structure and phase transformation of lanthanum chromate. J. Mater. Sci., 1996, 31(2): 551.

[9] Yang Z H, Lin Y S. Synergetic thermal effects for oxygen sorption and order-disorder transition on perovskite-type oxides. Solid State Ionics, 2005, 176(1-2): 89.

[10] Kruidhof H, Bouwmeester H J M, Doorn R H E V, Burggraaf A J. Influence of order-disorder transitions on oxygen permeability through selected nonstoichiometric perovskite-type oxides. Solid State Ionics, 1993, 63-65: 816.

[11] Ramos T, Atkinson A. Oxygen diffusion and surface exchange in $\mathrm{La}_{1-x} \mathrm{Sr}_{x} \mathrm{Fe}_{0.8} \mathrm{Cr}_{0.2} \mathrm{O}_{3-\delta}(x=0.2,0.4$ and 0.6). Solid State Ionics, 2004, 170(3-4): 275.

[12] Kharton V V, Yaremchenko A A, Valente A A, Sobyanin V A, Belyaev V D, Semin G L, Veniaminov S A, Tsipis E V,
Shaula A L, Frade J R, Rocha J. Methane oxidation over Fe-, Co-, Ni- and V-containing mixed conductors. Solid State Ionics, 2005, 176(7-8): 781.

[13] Voorhoeve R J H, Remeika J P, Trimble L E. Defect chemistry and catalysis in oxidation and reduction over perovskitetype oxides. Ann. N.Y. Acad. Sci., 1976, 272: 3.

[14] Zeng Y, Tamhankar S, Ramprasad N, Fitch F, Acharya D, Wolf R. A novel cyclic process for synthesis gas production. Chem. Eng. Sci., 2003, 58(3-6): 577.

[15] Isupova L A, Yakovleva I S, Alikina G M, Rogov V A, Sadykov V A. Reactivity of $\mathrm{La}_{1-x} \mathrm{Sr}_{x} \mathrm{FeO}_{3-y}(x=0-1)$ perovskites in oxidation reactions. Kinet. Catal., 2005, 46(5): 729.

[16] Ueda W, Chen C L, Asakawa K, M O Yoshihiko, Ikawa T. Catalytic properties of tricomponent metal oxides having the scheelite structure: II. Structural stability in the reduction-oxidation cycle. J. Catal., 1986, 101(2): 369. 